\title{
Improvement of Human Resources Capacity and Management of Payo Agro Tourism as an Efforts to Improve Local Economy
}

\author{
Peningkatan Kapasitas Sumber Daya Manusia dan Pengelolaan Agrowisata Payo \\ Sebagai Upaya Peningkatan Ekonomi Lokal \\ Adek Kurnia Fiza $\left.{ }^{*}\right) 1$, Ernawati ${ }^{2}$, Arif Ardian ${ }^{3}$, R Susanti ${ }^{4}$ \\ 1234 Fakultas Pariwisata dan Perhotelan, Universitas Negeri Pandang... 1234 \\ *)Corresponding author, $\equiv$ sretnaningtyas@yahoo.com
}

(Di isi oleh editor) Revisi 10/12/2019; Diterima 60/01/2020; Publish 01/02/2020

Kata kunci:

pariwisata, pengelolaan, SDM, dampak ekonomi, agrowisata payo

\begin{abstract}
Abstrak
Pariwisata menjadi motor penggerak perekonomian di masyarakat, berbagai daerah telah mengaplikasikan pola tersebut, dan berhasil memberikan dampak positif. Kondisi tersebut melatarbelakangi penelitian tentang keberhasilan program pengabdian masyarakat dari tim Universitas Negeri Padang (UNP) di Kelurahan Tanah Garam. Penelitian dilakukan pada Juni hingga November 2019, metode yang digunakan adalah pendekatan kualitatif. Data primer diperoleh dari wawancara terhadap Kepala Dinas Pariwisata dan Kebudayaan Kota Solok, tokoh masyarakat di Tanah Garam, Pokdarwis Payo, dan anggota masyarakat di kawasan Payo (Tanah Garam). Wawancara dilakukan sesuai dengan pedoman terkait keberhasilan program pengabdian masyarakat UNP dalam meningkatkan kapasitas sumber daya manusia (SDM) dan kemampuan pengelolaan agrowisata Payo, sehingga memberikan pengaruh ekonomi bagi masyarakat. Hasil penelitian menunjukkan bahwa program pengabdian berhasil meningkatkan perekonomian masyarakat setelah kemampuan pengelolaan pariwisatanya bertambah.
\end{abstract}

\section{PENDAHULUAN}

Pariwisata merupakan industri jasa yang mampu memberikan dampak positif terhadap perekonomian khususnya masyarakat lokal. Dampak positif tersebut seperti adanya peningkatan perekonomian dengan menciptakan peluang kerja dan usaha bagi masyarakat lokal. Pariwisata telah menjadi konsep pembangunan bagi daerah yang memiliki potensi pariwisata, seperti Kota Solok. Rencana Pembangunan Jangka panjang (RPJP) tahun 2025 Kota Solok adalah menjadi pusat pendidikan, budaya dan daerah tujuan wisata dalam lingkungan masyarakat yang maju, mandiri dan sejahtera. Objek wisata yang menjadi andalan Kota Solok 
adalah agrowisata Payo di Kelurahan Tanah Garam, Kecamatan Lubuk Sikarah, Kota Solok Provinsi Sumatera Barat.

Pariwisata adalah kegiatan khusus yang dilakukan seseorang atau sekelompok orang di luar lingkungan rumahnya selama waktu tertentu sehingga mereka membutuhkan tempat tinggal sementara (Camillleri, 2018). Pariwisata merupakan kegiatan yang dilakukan di luar lingkungannya selama kurang dari satu tahun berturut-turut dengan tujuan berlibur, bisnis, dan keperluan lainnya. Pendapatan yang meningkat diberbagai daerah memberikan dampak terhadap pariwisata, masyarakat mulai menjadikan kegiatan wisata sebagai kebutuhan primer, karena perkembangan moda transportasi yang dapat diakses dengan harga yang kompetitif (UNWTO, 2017).

Seseorang disebut sebagai wisatawan ketika mereka secara sukarela meninggalkan lingkungan asalnya untuk mengunjungi lingkungan lain. Mereka terlibat dalam kegiatan yang berbeda dari kesehariannya, tanpa memperhatikan jauh atau dekatnya tujuan wisata (Dhalyana, 2013; Amalia, 2014; dan Arasli, 2014). Wisatawan diklasifikasikan menjadi dua jenis, yang tinggal selama lebih dan kurang dari dari 24 jam. Wisatawan yang bepergian untuk rekreasi, kesehatan, olahraga, liburan, belajar atau agama tujuan, kunjungan mereka dapat dikategorikan sebagai wisatawan yang berkunjung lebih dari 24 jam, meskipun mereka mengunjungi beberapa objek yang berbeda. Wisatawan yang datang selama kurang dari 24 jam biasanya merupakan wisatawan domestik dan pelancong yang transit dari perjalanan panjangnya (Prabhakaran, 2014; Liang, 2016; Chiappa, 2016); dan Ingkadija, 2016).

Pariwisata adalah bisnis prospektif yang mampu mendorong aspek ekonomi dan bisnis (Mathew, 2017). Pariwisata memberikan peluang kerja. Trend tujuan wisata favorit adalah agrowisata, pemandangan, warisan, dan wisata buatan seperti kebun binatang atau wisata kuliner. Sektor pariwisata mempengaruhi pertumbuhan ekonomi dan kesejahteraan masyarakat sekitar tujuan, dan memicu peningkatan kesejahteraan masyarakat harus menjadi tujuan kebijakan kegiatan pariwisata.

\section{METODE PELAKSANAAN}

Pendeketan dalam penelitian ini adalah deskriptif kualitatif, data yang diperoleh selama kegiatan di lapangan dideskripsikan sehingga dapat dipahami oleh pembaca secara lebih sederhana. Pengumpulan data dimulai dengan observasi terkait dengan kondisi kepariwisataan di kawasan Payo, kemudian diikuti dengan wawancara mendalam kepada informan kunci penelitian, dan terakhir didukung dengan data sekunder dari berbagai pihak yang memiliki keterkaitan dengan tema penelitian. Karakteristik utama dan keunggulan penelitian kualitatif adalah menghasilkan informasi terkait dengan pengalaman, makna, dan pemahaman orangorang yang berpartisipasi dalam penelitian. Pariwisata erat kaitannya dengan kegiatan yang dilakukan oleh masyarakat dan pemangku kepentingan yang terlibat.

\section{HASIL DAN PEMBAHASAN}

Dampak selalu terkait dengan faktor ekonomi, sosial-budaya, dan aspek lingkungan. Faktor ekonomi merupakan dampak utama yang dapat dirasakan oleh masyarakat, salah satu bentuk nyatanya adalah penghasilan yang lebih baik, melalui terbukanya peluang kerja. Pariwisata juga mendorong peningkatan infrastruktur yang lebih baik. Pariwisata juga menghasilkan bisnis baru yang dapat dikelola oleh masyarakat dengan modal ekonomi kecil. Masyarakat adalah salah satu komponen yang mempengaruhi pengembangan pariwisata lokal, perannya sangat penting. Komunitas lokal adalah elemen dasar dari pengembangan pariwisata 


\section{Suluah Bendang: Jurnal Ilmiah Pengabdian Kepada Masyarakat}

Vol.20, No.2, 2020

Adek Kurnia Fiza 1, Ernawati 2, Arif Ardian 3, R Susanti 4

modern. Mereka berperan sebagai penyedia akomodasi, katering, informasi, transportasi, fasilitas dan layanan untuk mendukung keberlangsungan pariwisata.

Kawasan Agrowisata Payo

Kawasan Payo memiliki peluang pariwisata yang cukup prospektif, karena selain keindahan alam yang asri, juga memiliki potensi pertanian yang dapat dikembangkan sebagai Kawasan Agowisata. Bersamaan dengan hal itu, daerah kawasan alam yang asri dan pedesaan berpeluang besar untuk dikembangkan menjadi pariwisata yang produktif (Danamik,dkk, 2018). Potensi lain dalam kawasan agrowisata Payo diantaranya adalah Puncak Bidadari, Kawasan Are Batu Patahyang, Flora dan Fauna, Hutan, sungai - sungai dan lain-lain. Kawasan agrowisata Payo terletak di Kelurahan Tanah Garam, Kecamatan Lubuk Sikarah, Kota Solok Provinsi Sumatera Barat. Lokasi kawasan agrowisata Payo mudah dijangkau dari kota solok dengan jarak sekitar 30 menit dengan menggunakan kendaraan pribadi. Selain itu, kota solok dikelilingi wilayah kabupaten solok dengan batas-batas wilayah sebagai berikut: Utara (berbatasan dengan Kecamatan Kubung dan Kecamatan X Koto Siatas, Kabupaten Solok), Selatan (Berbatasan dengan Kecmatan Kubung Kabupaten Solok), Timur (Berbatasan dengan Kecamtan Kubung, Kecamatan X Koto Siatas, IX Koto Sungai Lasi Kabupaten Solok), Barat (Berbatasan dengan kecamatan Pauh dan Kecamatan Koto Tengah Kota padang).

Pengembangan kawasan agrowisata Payo menjadi solusi bagi maysarakat lokal yang ingin meningkatkan perekonomiannnya selain dari penghasilan utamanya yaitu pertanian dan perkebunan. Adapun komoditas pertanian yang dijumpai terdiri dari padi sawah, tanaman lahan kering (jagung, kacang tanah, ubi jalar), hortikultura sayuran (bawang merah, cabai, buncis, kacang panjang, petai dan jengkol), tanaman rempah dan obat (kunyit, jahe), tanaman hias (bunga krisan, mawar), hortikultura buah (alpukat, rambutan, pisang, manggis, jeruk) dan tanaman tahunan (kopi, kakao, cengkeh, kayu manis, kemiri). Komoditas pertanian tersebut sebagai dasar utama dikembangkannya konsep Agrowisata. Pada hakekatnya agrowisata merupakan suatu kegiatan yang mengintegrasikan pertanian dan pariwisata sehingga membentuk suatu daya tarik wisata yang menarik (Utama dan Junaedi, 2015). Daya tarik tersebut berupa pemandangan alam pertaniannya, Keunikan dan keragaman keanekaragaman pertanian serta teknologi pertanian yang digunakan baik bersifat tradisional maupun modern. Aktivitas dalam kegiatan pertanian tersebut menjadi daya tarik utama dalam pengembangan agrowisata.

Konsep agrowisata bukan hanya memanfaatkan keindahan alam pertanian namun juga memanfaatkan teknologi pertanian atau pengelolaan pertanian yang dilakukan oleh masyarakat lokal. Adanya perpaduan pontensi alam pertanian dan kondisi masyarakat perdesaan menjadi satu kesatuan potensi yang menarik dalam pengembangan agrowisata Payo. Selain itu, Kegiatan yang dapat dikembangakan dalam kawasan agrowisata Payo adalah seperti kegiatan haiking/trekking, kegiatan outbond, kegiatan perkemahan, kegiatan wisata pengetahuan ilmiah, dan kegiatan interaksi dengan satwa. Dalam mengembangkan kegiatan-kegiatan pariwisata tersebut perlu adanya kesiapan Sumber Daya Manusia sebagai penggerak kemajuan destinasi wisata.

Kapasitas Sumber Daya Manusia

Masyarakat lokal kawasan agrowisata Payo belum memaksimalkan potensi pariwisata yang ada, sehingga perlu memetakan dan menginterpretasi potensi kawasan agrowisata. Pengelolaan destinasi wisata penting mempertimbangkan kondisi sosial masyarakat Payo. Masyarakat Payo diberikan peran sebagai pengambil keputusan yang berkolaborasi dengan akademisi, pemerintahan dan swasta. Pengembangan pariwisata yang melibatkan peran 
masyarakat lokal secara langsung akan memberikan dampak positif terhadap kesejahteraannya. Kesadaran masyarakat lokal akan pariwisata masih kurang, hal ini terindikasi oleh minimnya masyarakat yang berperan aktif terhadap pengembangan agrowisata Payo. Masyarakat lokal yang penghasilan utamanya adalah pertanian dan perkebunan belum sepenuhnya menyadari bahwa potensi yang mereka miliki layak dikembangkan sebagai destinasi agrowisata.

Sosialisasi sadar wisata sebagai solusi bagi masyarakat yang pada tahap awal masih kurang kesadarannya terhadap pariwisata. Melalui sosialisasi sadar wisata akan membuka cakrawala pengetahuan masyarakat sehingga mereka dapat termotivasi untuk mengembangkan pariwisata. Pelatihan peningkatan kapasitas SDM bagi masyarakat lokal dilakukan di kawasan agrowisata Payo. Setelah masyarakat paham mengenai potensi dan peluang pariwisata yang dimilikinya, tahap selanjutnya adalah memberikan pelatihan peningkatan kapasistas SDM. Dalam pelatihan peningkatan kapasitas SDM diharapkan Masyarakat lokal memiliki kompetensi dalam mengelola agrowisata Payo.

Peningkatan Ekonomi

Kondisi masyarakat kawasan agrowisata Payo masih tergolong rendah perekonomiannya dan pada umumnya pekerjaannya adalah petani dan pekebun. Dengan memanfaatkan pertanian yang ada tanpa mengubah pekerjaan dasar masyarakat lokal dapat memberikan peningkatan perekonomian. Pengembangan pariwisata sejatinya tidak perlu mengubah pekerjaan utamanya, namun menambahkan keahliannya dalam pelayanan pariwisata. Pemanfaatan pertanian dan perkebunan sebagai pariwiata akan memberikan nilai tambah dari penghasilan utamanya. Jadi seorang petani dan pekebun tetaplah menekuni profesinya, hanya mereka diberikan pelatihan bagaimana cara melayani wisatawan secara baik.

Program pengabdian yang dilakukan di Payo menunjukkan peningkatan ekonomi sebagai berikut:

1. Terbentuknya usaha pariwisata Payo Nature di objek wisata

2. Perluasan kesempatan kerja bagi pemuda dan pemudi selain di sektor pertanian

3. Peningkatan pendapatan setelah meningkatnya kunjungan wisatawan

4. Distribusi pendapatan/keuntungan diantara seluruh pengelola wisata (pokdarwis)

5. Penyediaan fasilitas dan paket wisata tambahan (tracking)

6. Terbukanya jaringan untuk pengembangan pasarwisata yang berkelanjutan

Peningkatan ekonomi tersebut berawal dari kegiatan kerjasama antara Dinas Pariwisata Kota Solok dengan Fakultas Pariwisata dan Perhotelan Universitas Negeri Padang. Tindak lanjut dari kerjasama tersebut adalah pengiriman proposal pengabdian oleh tim UNP yang didanai oleh LP2M UNP tahun anggaran 2019. Proposal tersebut merupakan modal bagi masyarakat dan pengelola pariwisata di kawasan Payo, dengan pendampingan dari dosen-dosen UNP.

\section{Keberhasilan Program Pengabdian Masyarakat}

Keberhasilan program pengabdian pada masyarakat di kawasan Payo dapat dilihat dari peran masyarakat dalam hal partisipasi, pemberdayaa Pada tahap pertama tim pengabdi melakukan pertemuan dengan masyarakat lokal membahas program bersama tokoh masyarakat dan pejabat kelurahan setempat. Dari pertemuan FGD yang dilaksanakan, masyarakat menunjukkan peran aktif dalam melaksanakan program pelatihan, terlebih setelah mereka memahami dampak positif dari pelaksanakaan kegiatan tersebut. Narasumber yang kompeten dihadirkan untuk memberikan pengetahuan bagi masyarakat terkait dengan kebutuhan masyarakat dalam mengelola kepariwisataannya. Masyarakat bekerjasama dengan para narasumber untuk mengeksplorasi potensi, sekaligus mengelola objek yang telah dimiliki sehingga memberikan hasil yang berkelanjutan. Masyarakat bukan sekedar belajar teori, tetapi 


\section{Suluah Bendang: Jurnal IImiah Pengabdian Kepada Masyarakat}

mengaplikasikan secara langsung ilmu yang telah diperoleh dari para narasumbe, seperti contohnya mengaplikasikan kemampuan berbahasa asing, melakukan pengelolaan objek, dan melakukan pengelolaan sumber daya manusia untuk mendukung seluruh kegiatan kepariwisataannya.

Hasil monitoring dan evaluasi program menunjukkan hasil yang baik, masyarakat mampu mengaplikasikan teori dalam praktek secara tepat. Salah satu indikator nyata adalah terbukanya warung yang berada di kawasan objek wisata, yang menyediakan makanan dan minuman ringan yang dibutuhkan oleh wisatawan. Tidak hanya sekedar mampu menjual, anggota pokdarwis sebagai pengelola pariwisata mampu untuk mengelola keuangannya dengan baik. Laporan modal dan keuntungan menjadi indikator keberhasilan program tersebut.

\section{KESIMPULAN}

Kegiatan pengabdian pada masyarakat dengan judul "Peningkatan kapasitas sumber daya manusia dan pengelolaan agrowisata payo sebagai upaya peningkatan ekonomi lokal di Kelurahan Tanah Garam, Kecamatan Lubuk Sikarah, Kota Solok" oleh tim pengabdi dari Fakultas Pariwisata dan Perhotelan, Universitas Negeri Padang telah berhasil memberikan dampak signifikan sesuai dengan tujuan yang diharapkan. Kapasitas SDM Pariwisata dalam melakukan pengelolaan atraksi wisata meningkat, dari kondisi ketidaktahuan menjadi handal, seperti dalam memberikan pelayanan kepada wisatawan. Kegiatan pengabdian juga berhasil membantu masyarakat untuk meningkatkan perekonomiannya dengan terbukanya unit usaha yang bertujuan untuk memenuhi kebutuhan wisatawan. Pariwisata di Kawasan Payo, terutama di agrowisata Payo dapat semakin berkembang dengan dukungan dari berbagai pihak, salah satunya melalui kerjasama antara Pemerintah, Universitas, dan tentu saja Masyarakat setempat. Pada penelitian selanjutnya, hal yang penting diungkap adalah bagaimana untuk semakin menarik kedatangan wisatawan, sehingga upaya masyarakat dalam mengembangkan dan mengelola atraksi wisatanya dapat memberikan hasil ekonomi yang lebih signifikan.

\section{DAFTAR PUSTAKA}

Amalia, M. Dan Sumarti, T. (2014). Peluang usaha serta kerja akibat kehadiran wisatawan pada komunitas Tugu. Jurnal Sosiologi Pedesaan. 8 (2), 09.

Arasli, H. dan Baradarani, S. (2014). European tourist perspective on destination satisfaction in Jordan's industries. Procedia Social and Behavioral Sciences, 109, 1416-1425.

Camilleri, M. A. (2018). The Tourism Industry: An Overview. In Travel Marketing, Tourism Economics and the Airline Product (Chapter 1, pp. 3-27). Cham, Switzerland: Springer Nature.

Chiappa, G. D., Atzeni, M., dan Ghasemi, V. (2016). Community-based collaborative tourism planning in islands: a cluster analysis in the context of Costa Smeralda. Journal of Destination Marketing \& Management.

Dhalyana, D. dan Adiwibowo, S. (2013). Pengaruh taman wisata alam Pangandaran terhadap kondisi sosial ekonomi masyarakat (Studi: Desa Pangandaran, Kecamatan Pangandaran, Kabupaten Ciamis, Propinsi Jawa Barat). Jurnal Sosiologi Pedesaan, 7(3), 214.

Ingkadijaya, R., Damanik, J., Putra, H. S. A., dan Nopirin. (2016). Tourist activities contribution on family cohesion in Radzi, $S M$, et al (eds), heritage, culture, and society: research agenda and best practice in the hospitality \& tourism industry. London: Taylor \& Francis Group.

Liang, Z. X., dan Hui, T. K. (2016). Residents' quality of life and attitudes toward tourism development in China. Journal Tourist Management, 57. 
Mathew, P. V., dan Sreejesh, S. (2017). Impact of responsible tourism on destination sustainability and quality of life of community in tourism destinations. Journal of Hospitality and Tourism Management, 31, 83.

Prabhakaran, S., Nair, V., dan Ramachandran, S. (2014). Community participation in rural tourism: towards a conceptual framework. Procedia Social and Behavioral Sciences, 144, 290.

Improvement of Human Resources Capacity and Management of Payo Agro Tourism as an Efforts to Improve Local Economy | 85 Available online: $\mathrm{http}: / /$ sulben.ppj.unp.ac.id 